\section{Original Article}

D) Check for updates

\section{OPEN ACCESS}

Received: Apr 20, 2018

Revised: Jul 4, 2018

Accepted: Jul 11, 2018

Correspondence to

Steven D. Miller

Division of Pediatric Gastroenterology \&

Hepatology, Johns Hopkins University School of Medicine, 600 N. Wolfe St., CMSC 2-116,

Baltimore, MD 21287, USA

E-mail: smill132@jhmi.edu

Copyright (c) 2019 by The Korean Society of Pediatric Gastroenterology, Hepatology and Nutrition

This is an open-access article distributed under the terms of the Creative Commons Attribution Non-Commercial License (https:// creativecommons.org/licenses/by-nc/4.0/) which permits unrestricted non-commercial use, distribution, and reproduction in any medium, provided the original work is properly cited.

Funding

Dr. Hutfless received an investigator-initiated research award from Luitpold Pharmaceuticals (No Grant \#). This paper was not supported by that award. Dr. Miller received an NIH T32 training grant (Grant \# T32HD044355) to cover his salary during the period this paper was written.

\section{Conflict of Interest}

The remaining authors (Carmelo Cuffari, Eboselume Akhuemonkhan, Anthony L. Guerrerio, Harold Lehmann) have no relevant sources of funding or conflicts of interest to declare.

\title{
Anemia Screening, Prevalence, and Treatment in Pediatric Inflammatory Bowel Disease in the United States, 2010-2014
}

\section{Steven D. Miller, ' Carmelo Cuffari, ' Eboselume Akhuemonkhan, ${ }^{2}$ Anthony L. Guerrerio, ${ }^{1}$ Harold Lehmann, ${ }^{3}$ and Susan Hutfless ${ }^{4,5}$}

'Division of Pediatric Gastroenterology \& Hepatology, Johns Hopkins University School of Medicine, Baltimore, MD, USA

${ }^{2}$ Department of Allopathic Internal Medicine Residency, The Wright Center for Graduate Medical Education, Scranton, PA, USA

${ }^{3}$ Division of Health Science Informatics, Johns Hopkins University School of Medicine, Baltimore, MD, USA ${ }^{4}$ Division of Gastroenterology \& Hepatology, Johns Hopkins University School of Medicine, Baltimore, MD, USA ${ }^{5}$ Division of Gastroenterology and Hepatology, Johns Hopkins Bloomberg School of Public Health, Baltimore, MD, USA

\section{ABSTRACT}

Purpose: We examined the prevalence of anemia, annual screening for anemia, and treatment of anemia with iron among children with inflammatory bowel disease (IBD). Methods: A retrospective study of U.S. pediatric patients with IBD was performed in the MarketScan commercial claims database from 2010-2014. Children (ages 1-21) with at least two inpatient or outpatient encounters for IBD who had available lab and pharmacy data were included in the cohort. Anemia was defined using World Health Organization criteria. We used logistic regression to determine differences in screening, incident anemia, and treatment based on age at first IBD encounter and sex.

Results: The cohort $(n=2,446)$ included 1,560 Crohn's disease (CD) and 886 ulcerative colitis (UC). Approximately, $85 \%$ of $\mathrm{CD}$ and $81 \%$ of UC were screened for anemia. Among those screened, $51 \%$ with $\mathrm{CD}$ and $43 \%$ with UC had anemia. Only $24 \%$ of anemia patients with CD and 20\% with UC were tested for iron deficiency; $85 \%$ were iron deficient. Intravenous (IV) iron was used to treat $4 \%$ of $\mathrm{CD}$ and $4 \%$ UC patients overall and $8 \%$ of those with anemia. Conclusion: At least $80 \%$ of children with IBD were screened for anemia, although most did not receive follow-up tests for iron deficiency. The $43 \%-50 \%$ prevalence of anemia was consistent with prior studies. Under-treatment with IV iron points to a potential target for quality improvement.

Keywords: Crohn disease; Screening; Ulcerative colitis; Anemia; Iron-deficiency

\section{INTRODUCTION}

Crohn's disease (CD) and ulcerative colitis (UC) are the chronic inflammatory bowel disease (IBD) [1]. Up to $25 \%$ of patients with IBD are diagnosed in childhood or adolescence, and the incidence is increasing $[1,2]$. In addition to the typical symptoms of IBD such as bloody 
stools and abdominal pain, IBD is associated with a multitude of systemic complications, the most prevalent of which is anemia [3].

Anemia significantly worsens quality of life in patients with IBD [4,5], and anemia can result in worsened cognitive outcomes [6]. The most common etiologies of anemia in children with IBD are iron deficiency and anemia of chronic disease [7]. Iron deficiency anemia can result from insufficient dietary iron intake due to altered diet, diminished uptake in the small bowel, and chronic blood loss due to mucosal ulcerations [8]. Both iron deficiency anemia and anemia of chronic disease are associated with ongoing inflammation $[3,4,8,9]$. Other risk factors associated with development of anemia among children with IBD include more extensive disease [2,5,8-10], poor growth [4,9], presence of CD as opposed to UC [8], and African American ethnic background [7]. Diagnosis of anemia in pediatric IBD is made according to World Health Organization (WHO) standards for hemoglobin (Hgb) and hematocrit (Hct) by age (Supplementary Table 1) [7,11]. When anemia is present, iron deficiency and anemia of chronic disease are diagnosed with further laboratory tests, including ferritin and C-reactive protein (CRP) [7].

The pathways from screening to diagnosis and then treatment of anemia among children with IBD are based on guidelines for adults with IBD published in 2007 [9] and 2015 by the European Crohn's and Colitis Organization (ECCO) [7]. Pediatric IBD guidelines suggest screening for anemia and iron deficiency during outpatient visits [12], but these recommendations lack specificity, so in practice the adult guideline is used. ECCO recommends at least annual measurement of $\mathrm{Hgb} / \mathrm{Hct}$ for anemia, screening for iron deficiency after anemia is diagnosed, and treatment with intravenous (IV) iron among patients with active disease and oral iron for those with controlled disease who can tolerate the gastrointestinal side effects. Recent studies have suggested that oral iron use may trigger mucosal harm or adverse events not triggered by IV iron $[10,13,14]$ and that IV iron results in rapid and complete resolution of anemia in children [15-17]. Choice of route therefore depends on disease activity, degree of anemia and oral iron tolerance [7].

Previous small to medium sized studies conducted in referral centers found that anemia is common in pediatric patients with IBD and these patients often go untreated, similar to adult IBD [3,4,18-37] (Table 1). No studies have examined adherence to anemia screening guidelines in pediatrics.

We examined the prevalence, screening and treatment of anemia as well as associated factors in a real-world cohort of pediatric IBD patients using MarketScan ${ }^{\circledR}$ Claims and Encounters database 2010-2014.

\section{MATERIALS AND METHODS}

This is a retrospective study of children with IBD using the MarketScan database from 2010-2014. This database contains information obtained from large employers, health plans, government, and public organizations. MarketScan incorporates billing data, labs, and pharmacy data from both inpatient and outpatient contexts for patients with private insurance including all 50 states [38]. The database consists of encounters of insured employees and their dependents through employer provided health insurance plans. Patients who received Medicaid or Medicare were not included. Claims from individuals who switch health plans during their employment are included. However, claims are not linked across employers. 
Table 1. Summary of the 17 studies on prevalence and treatment of anemia among children with IBD

\begin{tabular}{|c|c|c|c|c|}
\hline Author; Location & Year & No. of pediatric IBD patients & $\begin{array}{l}\text { Prevalence of anemia among } \\
\text { screened patients }\end{array}$ & Prevalence of Fe treatment \\
\hline \multirow[t]{2}{*}{ Miller; United States* } & 2018 & $\mathrm{CD} n=1,560^{*}$ & CD $49 \%{ }^{*}$ & CD IV Fe $4 \%{ }^{*}$ \\
\hline & & UC $n=886^{*}$ & UC $43 \%{ }^{*}$ & UC IV Fe $3 \%{ }^{*}$ \\
\hline \multirow[t]{3}{*}{ Wikholm; Sweden } & 2016 & $C D n=28$ & $46 \%{ }^{\dagger}$ & Oral Fe $40 \%{ }^{\dagger}$ \\
\hline & & UC $n=45$ & & Oral + IV Fe $4 \%^{\dagger}$ \\
\hline & & IBDU $n=17$ & & IV Fe $3 \%{ }^{\dagger}$ \\
\hline \multirow[t]{2}{*}{ Sjöberg; Sweden } & 2014 & $C D n=44$ & $55 \%{ }^{\dagger}$ & Not reported \\
\hline & & UC $n=38$ & & \\
\hline \multirow[t]{2}{*}{ Van Biervliet; Belgium } & 2014 & $C D n=83$ & CD $61 \%$ & CD Oral Fe $12 \%$ \\
\hline & & & & CD IV Fe 4\% \\
\hline \multirow[t]{3}{*}{ Gerasimidis; United Kingdom } & 2013 & $C D n=122$ & CD $72 \%$ & CD Oral Fe $34 \%$ \\
\hline & & UC $n=51$ & UC $69 \%$ & UC Oral Fe $58 \%$ \\
\hline & & IBDU $n=11$ & IBDU $66 \%$ & \\
\hline \multirow[t]{3}{*}{ Goodhand; United Kingdom } & 2012 & $\mathrm{CD} n=73$ & $57 \%{ }^{\dagger}$ & Oral Fe $20 \%{ }^{\dagger}$ \\
\hline & & UC $n=31$ & & IV Fe $10 \%{ }^{\dagger}$ \\
\hline & & IBDU $n=9$ & & \\
\hline \multirow[t]{2}{*}{ Wiskin; United Kingdom } & 2012 & $C D n=46$ & $75 \%{ }^{\dagger}$ & Not reported \\
\hline & & UC $n=34$ & & \\
\hline \multirow[t]{3}{*}{ White; United States } & 2008 & $C D n=860$ & $20 \%{ }^{\dagger}$ & Not reported \\
\hline & & UC $n=409$ & & \\
\hline & & IBDU $n=137$ & & \\
\hline \multirow[t]{2}{*}{ Mack; United States and Canada } & 2007 & $C D n=392$ & CD $69 \%$ & Not reported \\
\hline & & UC $n=134$ & UC $36 \%$ & \\
\hline Howarth; United Kingdom & 2007 & $\mathrm{n}=32^{\dagger}$ & $63 \%{ }^{\dagger}$ & Not reported \\
\hline Thayu; United States & 2005 & $C D n=78$ & CD 77\% & Not reported \\
\hline \multirow[t]{2}{*}{ Khan; United States } & 2002 & UC $n=51$ & CD $41 \%$ & Not reported \\
\hline & & $C D n=39$ & UC $41 \%$ & \\
\hline \multirow[t]{2}{*}{ Revel-Vilk; Israel } & 2000 & $C D n=50$ & $41 \%{ }^{\dagger}$ & Not reported \\
\hline & & UC $n=13$ & & \\
\hline \multirow[t]{2}{*}{ Gryboski; United States } & 1994 & $C D n=40$ & CD $75 \%$ & Not reported \\
\hline & & UC $n=38$ & UC $84 \%$ & \\
\hline Thomas; United States & 1989 & $C D n=24$ & CD $71 \%$ & Not reported \\
\hline Burbige; United States & 1979 & $C D n=58$ & CD $50 \%$ & Not reported \\
\hline Beeken; United States & 1975 & $C D \mathrm{n}=11$ & CD 73\% & Not reported \\
\hline
\end{tabular}

Review of the published literature on incidence and rates of treatment of anemia in pediatric IBD.

IBD: inflammatory bowel disease, CD: Crohn's disease, UC: ulcerative colitis, IBDU: inflammatory bowel disease unspecified, IV: intravenous, Fe: iron, n: the number of pediatric patients in the study.

${ }^{*}$ Current study; ${ }^{\dagger}$ IBD subtype not specified, aggregate counts only provided.

Children and young adults with at least two inpatient or outpatient encounters for IBD based on International Classification of Diseases, Ninth Edition, Clinical Modification codes 555 for $\mathrm{CD}$ or 556 for UC were eligible. Patients age 1 to 21 years old were included. Patients less than 1 year old were excluded as data suggests they have a greater likelihood of monogenic IBD, which is a distinct pathophysiologic entity [39]. Other exclusion criteria included lack of lab or pharmacy benefit. Patients with more encounters for CD than UC were classified as CD and similarly for UC. Patients with UC were censored at the time of colectomy. Lab tests were identified using Logical Observation Identifiers Names and Codes (LOINC) [40].

Anemia was defined using WHO standards for age (Supplementary Table 1). Individuals with anemia were assessed for iron-deficiency per WHO standards using ferritin $<30 \mathrm{ng} / \mathrm{mL}$ for individuals with normal CRP and ferritin $<100 \mathrm{ng} / \mathrm{mL}$ for individuals with elevated CRP [7]. Adherence to annual screening was examined by calculating yearly intervals from the patient's first date of anemia screening allowing a 3-month annual leeway period. Dates of inpatient stay were used as proxy dates for anemia screening because inpatient laboratory claims are not available. Laboratory values were required for contribution to the anemia 
prevalence analysis. This methodology was outlined in a prior paper [35]. Anemia treatment was determined by prescriptions for oral or IV iron medications or by Current Procedural Terminology codes for infusion. Other demographic and clinical factors were assessed for each patient including sex, age, number of IBD outpatient visits, number of hospital admissions, and medications used for treatment of IBD.

Statistical analysis was conducted using SAS 9.4 (SAS Institute, Cary, NC, USA). Frequency distributions, median and range for demographic values were calculated. Prevalence of screening for anemia was calculated based on the number of individuals who had a test result for Hgb, Hct or an inpatient stay after their first IBD encounter over the total eligible population. Inpatient stay was used as a proxy for screening given the common clinical practice of obtaining Hgb/Hct on children admitted to the hospital who have IBD. Frequency of testing was calculated to assess annual screening recommendation by examining the proportion of IBD patients with at least one screening or inpatient stay per year after their first test. Prevalence of anemia was calculated by dividing the number of individuals who met WHO criteria for anemia over the study period by the total number of individuals with $\mathrm{Hgb}$ or Hct results. Iron deficiency was assessed using the WHO standards. Prevalence of iron treatment was calculated by dividing the number of individuals who received oral or IV iron during the study period by the total number of IBD patients and separately among those with anemia. Logistic regression was used to examine age and sex differences in screening, prevalence of anemia and treatment. The Johns Hopkins Institutional Review Board approved this study (IRB00054790).

\section{RESULTS}

\section{Demographics}

Of 380,386 patients with at least two IBD encounters during 2010-2014, 44,862 had pharmacy benefit and laboratory information available and 2,446 (1,560 CD and 886 UC) were aged 1-21 with sufficient follow-up (Supplementary Fig. 1). Included individuals were predominately adolescents (median age 17 years for $\mathrm{CD}$ and 18 years for UC), almost equally split between male and female ( $48 \%$ female CD, $53 \%$ female UC), and had a median followup of 2 years for both CD and UC. The $35 \%$ of CD and $27 \%$ of UC patients had at least one IBD-related hospitalization. The $67 \%$ of $\mathrm{CD}$ and $50 \% \mathrm{UC}$ had ten or more IBD-related outpatient visits. Steroids were the most common medication used by CD patients (55\%) and aminosalicylates were the most common medication in UC (65\%) (Table 2).

\section{Prevalence of anemia screening}

Among patients with CD, $85 \%$ were screened for anemia at least once, while $81 \%$ of UC patients were screened (Fig. 1). For patients with $\mathrm{CD}$, there was no significant difference between males and females (chi-squared $p=0.99$ ), though for UC, males were screened more (chi-squared $p=0.02$ ) (Table 3). For patients with CD, children aged 12-13 were screened more than other age categories (chi-squared $p=0.05$ ). Patients with $\mathrm{UC}$ had no differences by age (Table 3).

\section{Prevalence of anemia among those screened}

Among screened patients ( $\mathrm{n}=1,849)$, anemia was present in $51 \%$ of $\mathrm{CD}$ and $43 \%$ of UC patients (Fig. 1). For both CD and UC patients, females were more often anemic than males (chi-squared $p<0.01$ ). Patients with $\mathrm{CD}$ had no differences by age, but children with UC aged 
Table 2. Demographic characteristics of children with IBD

\begin{tabular}{|c|c|c|}
\hline Characteristics & $\operatorname{CD}(n=1,560)$ & UC $(n=886)$ \\
\hline Median age at enrollment (Min-Max) & 17 y $(1-21)$ & 18 y (1-21) \\
\hline $1-4$ & 1.1 & 1.8 \\
\hline $5-11$ & 14 & 12.5 \\
\hline $12-13$ & 9.9 & 7.6 \\
\hline $14-21$ & 75 & 78.1 \\
\hline Female & 48.4 & 53.4 \\
\hline Median length of follow-up after first IBD encounter (Min-Max) & 2 y $(1-4.9)$ & 2 y $(1-4.9)$ \\
\hline \multicolumn{3}{|l|}{ IBD Hospitalizations } \\
\hline 0 & 65.1 & 73.4 \\
\hline 1 & 19.3 & 18.2 \\
\hline 2 & 7.2 & 4.2 \\
\hline$\geq 3$ & 8.4 & 4.3 \\
\hline \multicolumn{3}{|l|}{ Outpatient IBD visits } \\
\hline $1-10$ & 33.3 & 50.1 \\
\hline $10-20$ & 26.2 & 25.3 \\
\hline $20-50$ & 33 & 21.2 \\
\hline$\geq 50$ & 7.5 & 3.4 \\
\hline \multicolumn{3}{|l|}{ Ever use of IBD-related medications } \\
\hline Biologic & 40.1 & 8.6 \\
\hline Immunomodulator & 43.5 & 32.3 \\
\hline Steroid & 55.2 & 57.6 \\
\hline 5-ASA & 26.6 & 65 \\
\hline
\end{tabular}

Demographic characteristics of the cohort including age, sex, follow-up, hospitalizations and outpatient visits for IBD and IBD medications. Age, gender, and hospitalizations are presented as \% of overall cohort. IBD medications are presented as $\%$ of the cohort who has used each medication.

IBD: inflammatory bowel disease, 5-ASA: mesalamine-containing medication.

12-13 were more often anemic than other groups (chi-squared $p=0.03$ ) (Table 3). Of the CD patients with CRP results ( $n=739$ ), $60 \%$ of anemic patients had elevated CRP while $27 \%$ of non-anemic patients had elevated CRP. Of the UC patients with CRP results ( $\mathrm{n}=343), 45 \%$ of anemic patients had elevated CRP while $19 \%$ of non-anemic patients had elevated CRP.

\section{Prevalence of iron deficiency among those with anemia}

Among patients who met $\mathrm{WHO}$ criteria for anemia ( $\mathrm{n}=869)$ ), $24 \%$ of CD patients and $20 \%$ of UC patients had an associated ferritin and CRP measurement and could be assessed for iron-

Table 3. Anemia Screening, Prevalence, and Treatment by Age and Sex Among Children with IBD

\begin{tabular}{|c|c|c|c|c|c|c|c|}
\hline \multirow[t]{2}{*}{ Characteristics } & \multirow[t]{2}{*}{ Age (y) } & \multicolumn{2}{|c|}{$\mathrm{CD}(\%)$} & \multirow[t]{2}{*}{ Age $p$-value } & \multicolumn{2}{|c|}{ UC (\%) } & \multirow[t]{2}{*}{ Age $p$-value } \\
\hline & & Male & Female & & Male & Female & \\
\hline \multirow[t]{5}{*}{ Screening } & $1-4$ & 87.5 & 77.8 & 0.71 & 91.0 & 100.0 & 0.25 \\
\hline & $5-11$ & 87.8 & 86.5 & 0.52 & 82.2 & 84.9 & 0.39 \\
\hline & $12-13$ & 75.9 & 83.8 & 0.05 & 84.4 & 70.0 & 0.48 \\
\hline & $14-21$ & 85.9 & 85.2 & Reference & 84.4 & 77.4 & Reference \\
\hline & Sex $p$-value & 0.99 & & & 0.02 & & \\
\hline \multirow[t]{5}{*}{ Anemia prevalence } & $1-4$ & 50.0 & 50.0 & 0.98 & 14.3 & 0.0 & 0.09 \\
\hline & $5-11$ & 43.8 & 45.5 & 0.31 & 33.3 & 46.0 & 0.59 \\
\hline & $12-13$ & 50.9 & 57.4 & 0.32 & 42.9 & 80.0 & 0.03 \\
\hline & $14-21$ & 42.4 & 56.3 & Reference & 37.3 & 48.3 & Reference \\
\hline & Sex $p$-value & $<0.01$ & & & $<0.01$ & & \\
\hline \multirow[t]{5}{*}{ Treatment } & $1-4$ & 0.0 & 0.0 & 0.98 & 0.0 & 0.0 & 0.99 \\
\hline & $5-11$ & 2.4 & 6.3 & 0.36 & 2.2 & 1.5 & 0.13 \\
\hline & $12-13$ & 3.5 & 1.5 & 0.12 & 2.7 & 0.0 & 0.22 \\
\hline & $14-21$ & 4.3 & 7.4 & Reference & 4.1 & 6.2 & Reference \\
\hline & Sex $p$-value & 0.02 & & & 0.32 & & \\
\hline
\end{tabular}

Results are presented here of \% patients screened for anemia, \% patients with anemia, and \% patients treated for anemia broken down by IBD subtype, age, and sex. The $p$-values were generated from logistic regression models; age is adjusted for sex and vice versa. The $p$-values are provided to 2 decimal places. CD: Crohn's disease, UC: ulcerative colitis, IBD: inflammatory bowel disease. 

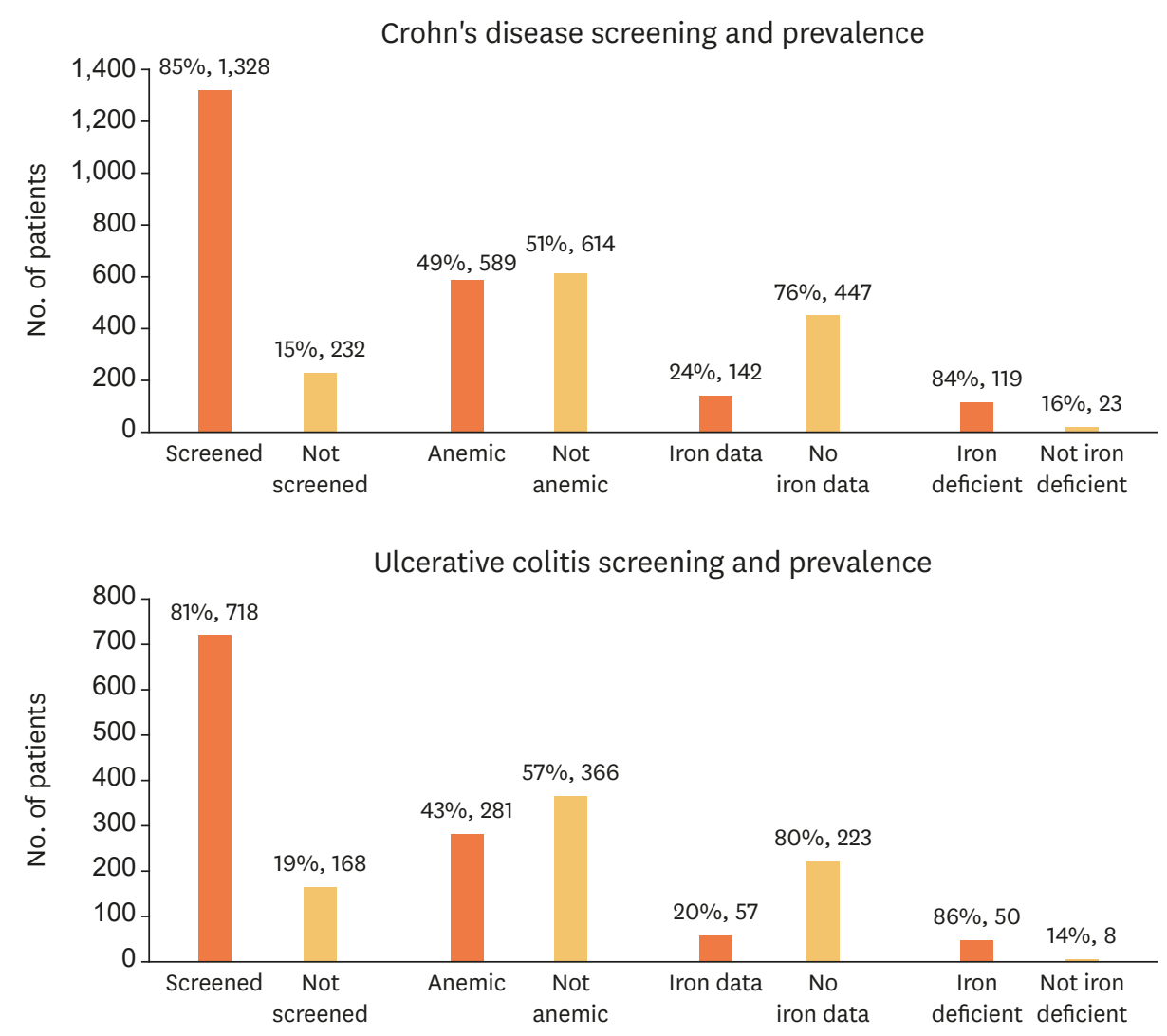

Fig. 1. Prevalence of screening, anemia and iron deficiency anemia among children with IBD. Results are presented here of the $\%$ and number of patients who were screened for anemia with $\%$ rounded to 0 decimal places. The number of screened patients was used to determine the $\%$ of patients with anemia. The number of anemic patients was used to determine the $\%$ of patients with lab evaluation for iron deficiency. The number of patients with sufficient iron data was used to determine the $\%$ of iron deficient patients.

IBD: inflammatory bowel disease, CD: Crohn's disease, UC: ulcerative colitis.

deficiency anemia. Of this screened sample, iron deficiency anemia was present in $84 \%$ of CD patients and $86 \%$ of UC patients (Fig. 1).

\section{Prevalence of treatment by anemia status}

Among patients with $\mathrm{CD}, 5 \%(\mathrm{n}=81)$ were administered iron, while $4 \%(\mathrm{n}=39)$ of UC patients were given iron. Only $1 \%$ of $C D$ and $1 \%$ of UC patients received oral iron. Among patients with anemia, $8 \%$ of both CD and UC patients received IV iron. Among patients with iron deficiency anemia, $13 \%$ of CD patients and $20 \%$ of UC patients received IV iron (Supplementary Fig. 2). Female children with CD were treated more often than males, however, there was no difference in treatment by sex with UC. There were no age differences in treatment (Table 3).

\section{Examination of the unscreened cohort}

Among patients with CD, 15\% were never screened, while 19\% of UC were never screened. Among unscreened patients, the age and sex distribution were similar to the rest of the cohort. In unscreened patients with $\mathrm{CD}, 49 \%$ had $<10$ outpatient visits. For unscreened patients with UC, $70 \%$ had $<10$ visits. Unscreened patients with CD were treated with biologics (31\%), immunomodulators (27\%), and steroids ( $41 \%$ ) compared to $40 \%, 44 \%$, and $55 \%$ among those screened. This pattern was similar for patients with UC (Supplementary Table 2). 


\section{DISCUSSION}

This is the first study to look at prevalence of anemia screening in a population of children with IBD, and as such has direct implications for current practice. At least $80 \%$ pediatric patients with either CD or UC were screened. Females with UC were screened less often than males and adolescents aged 14-21 were screened less often than children aged 12-13. Adolescent age and female gender may therefore be potential targets for quality improvement. Examination of the unscreened cohort revealed other potential clinical variables that require a more in-depth investigation including number of outpatient visits and treatment with IBD medications. It may be possible that some members of the unscreened cohort had less severe disease requiring less frequent screening, but this hypothesis requires further investigation.

Screening for iron deficiency among patients with anemia was quite low ( 1 in 5 IBD patients). ECCO guidelines recommend at least annual screening for iron deficiency with ferritin and screening every 3 months for patients with anemia [7]. This is another potential target for quality improvement, especially given the very high prevalence of iron deficiency among those who were tested.

The overall prevalence of anemia in this population is consistent with many of the prior single-center studies (Table 1). The robustness of this estimate across study designs suggests that nearly half of children with IBD are likely to benefit from iron therapy. The higher prevalence of anemia among patients with elevated CRP as opposed to normal CRP is also consistent with prior studies $[3,4,8,9]$, though further research is needed to explore which marker of disease activity is most clearly associated with development of anemia.

Compared with prior studies that looked at anemia treatment in children with IBD, prevalence of oral iron supplementation was overall much lower in this cohort, however MarketScan only includes prescription data and does not include over the counter utilization. Treatment with IV iron was similar to prior studies, especially those with laboratoryconfirmed anemia, of whom about $8 \%$ were treated in our study (Table 1).

There are several weaknesses in the data source upon which this study was based. Some demographic factors could not be determined from the data including patient race, patient socioeconomic status, subspecialty of the treating physician, and practice setting (e.g., academic vs. community). The potentially important sub-population of patients on Medicaid could not be examined in this cohort as MarketScan only includes privately insured patient data. Inpatient lab results could not be determined. We attempted to account for the lack of inpatient labs by presuming that patients were screened for anemia during inpatient encounters, which would over-estimate prevalence of screening. To limit this overestimation, we required that at least one outpatient lab result (related to anemia or otherwise) was available per child.

In summary, screening for anemia and diagnosis of anemia are common among children with IBD but screening for iron-deficiency anemia and iron treatment are not. Quality improvement initiatives might increase screening for iron-deficiency anemia among children with laboratory evidence for anemia and treatment with IV iron among children with active disease. This paper reconfirms the high prevalence of anemia among children with IBD, and raises the possibility of use of process markers such as rates of anemia screening and 
treatment as quality indicators. Increasing adherence to the process measures for screening and treatment of anemia may lead to improved outcomes for pediatric IBD.

\section{SUPPLEMENTARY MATERIALS}

\section{Supplementary Table 1}

Minimum hemoglobin and hematocrit levels used to define anemia in people living at sea level

Click here to view

\section{Supplementary Table 2}

Demographic characteristics of unscreened cohort

\section{Click here to view}

\section{Supplementary Fig. 1}

Inclusion criteria for pediatric CD and UC patients in MarketScan ${ }^{\circledR}$, 2010-2014. Inclusion and exclusion criteria used to define the cohort are reported with numbers of remaining patients provided at each stage of exclusion, represented as " $n=$ ".

Click here to view

\section{Supplementary Fig. 2}

Prevalence of Fe treatment among all patients, screened, anemic, and Fe deficiency anemic children with IBD. Anemia treatment by screening, anemia status, and Fe deficiency status. Results are presented here of the \% and number of patients with $\mathrm{CD}$ in the upper graph and UC in the lower graph who were treated with Fe with \% being rounded to 0 decimal places. The leftmost columns use the entire cohort as the denominator. The next set of columns uses screened patients as the denominator. The next set of columns uses patients with anemia as the denominator. The rightmost set of columns uses patients with Fe deficiency as the denominator.

Click here to view

\section{REFERENCES}

1. Benchimol EI, Fortinsky KJ, Gozdyra P, Van den Heuvel M, Van Limbergen J, Griffiths AM. Epidemiology of pediatric inflammatory bowel disease: a systematic review of international trends. Inflamm Bowel Dis 2011;17:423-39.

PUBMED | CROSSREF

2. Kelsen J, Baldassano RN. Inflammatory bowel disease: the difference between children and adults. Inflamm Bowel Dis 2008;14 Suppl 2:S9-11.

PUBMED | CROSSREF

3. Goodhand JR, Kamperidis N, Rao A, Laskaratos F, McDermott A, Wahed M, et al. Prevalence and management of anemia in children, adolescents, and adults with inflammatory bowel disease. Inflamm Bowel Dis 2012;18:513-9. PUBMED | CROSSREF

4. Danese S, Hoffman C, Vel S, Greco M, Szabo H, Wilson B, et al. Anaemia from a patient perspective in inflammatory bowel disease: results from the European Federation of Crohn's and Ulcerative Colitis Association's online survey. Eur J Gastroenterol Hepatol 2014;26:1385-91. PUBMED 
5. Wells CW, Lewis S, Barton JR, Corbett S. Effects of changes in hemoglobin level on quality of life and cognitive function in inflammatory bowel disease patients. Inflamm Bowel Dis 2006;12:123-30. PUBMED | CROSSREF

6. McCann JC, Ames BN. An overview of evidence for a causal relation between iron deficiency during development and deficits in cognitive or behavioral function. Am J Clin Nutr 2007;85:931-45. PUBMED | CROSSREF

7. Dignass AU, Gasche C, Bettenworth D, Birgegård G, Danese S, Gisbert JP, et al. European consensus on the diagnosis and management of iron deficiency and anaemia in inflammatory bowel diseases. J Crohns Colitis 2015;9:211-22. PUBMED | CROSSREF

8. Mücke V, Mücke MM, Raine T, Bettenworth D. Diagnosis and treatment of anemia in patients with inflammatory bowel disease. Ann Gastroenterol 2017;30:15-22. PUBMED

9. Gasche C, Berstad A, Befrits R, Beglinger C, Dignass A, Erichsen K, et al. Guidelines on the diagnosis and management of iron deficiency and anemia in inflammatory bowel diseases. Inflamm Bowel Dis 2007;13:1545-53. PUBMED | CROSSREF

10. Alleyne M, Horne MK, Miller JL. Individualized treatment for iron-deficiency anemia in adults. Am J Med 2008;121:943-8. PUBMED | CROSSREF

11. World Health Organization; United Nations Children's Fund; United Nations University. Iron deficiency anemia: assessment, prevention and control [Internet]. Geneva: World Health Organization; 2001 [cited 2017 Oct 22]. Available from: http://www.who.int/nutrition/publications/en/ida_assessment_prevention_control.pdf.

12. Rufo PA, Denson LA, Sylvester FA, Szigethy E, Sathya P, Lu Y, et al. Health supervision in the management of children and adolescents with IBD: NASPGHAN recommendations. J Pediatr Gastroenterol Nutr 2012;55:93-108. PUBMED | CROSSREF

13. de Silva AD, Tsironi E, Feakins RM, Rampton DS. Efficacy and tolerability of oral iron therapy in inflammatory bowel disease: a prospective, comparative trial. Aliment Pharmacol Ther 2005;22:1097-105. PUBMED | CROSSREF

14. Avni T, Bieber A, Steinmetz T, Leibovici L, Gafter-Gvili A. Treatment of anemia in inflammatory bowel disease--systematic review and meta-analysis. PLoS One 2013;8:e75540. PUBMED | CROSSREF

15. Stein RE, Plantz K, Maxwell EC, Mamula P, Baldassano RN. Intravenous iron sucrose for treatment of iron deficiency anemia in pediatric inflammatory bowel disease. J Pediatr Gastroenterol Nutr 2018;66:e51-5. PUBMED | CROSSREF

16. Valério de Azevedo S, Maltez C, Lopes AI. Pediatric Crohn's disease, iron deficiency anemia and intravenous iron treatment: a follow-up study. Scand J Gastroenterol 2017;52:29-33. PUBMED | CROSSREF

17. Danko I, Weidkamp M. Correction of iron deficiency anemia with intravenous iron sucrose in children with inflammatory bowel disease. J Pediatr Gastroenterol Nutr 2016;63:e107-11. PUBMED | CROSSREF

18. Sjöberg D, Holmström T, Larsson M, Nielsen AL, Holmquist L, Rönnblom A. Anemia in a populationbased IBD cohort (ICURE): still high prevalence after 1 year, especially among pediatric patients. Inflamm Bowel Dis 2014;20:2266-70. PUBMED | CROSSREF

19. Gerasimidis K, Barclay A, Papangelou A, Missiou D, Buchanan E, Tracey C, et al. The epidemiology of anemia in pediatric inflammatory bowel disease: prevalence and associated factors at diagnosis and follow-up and the impact of exclusive enteral nutrition. Inflamm Bowel Dis 2013;19:2411-22. PUBMED | CROSSREF

20. White JM, O'Connor S, Winter HS, Heyman MB, Kirschner BS, Ferry GD, et al. Inflammatory bowel disease in African American children compared with other racial/ethnic groups in a multicenter registry. Clin Gastroenterol Hepatol 2008;6:1361-9. PUBMED | CROSSREF

21. Mack DR, Langton C, Markowitz J, LeLeiko N, Griffiths A, Bousvaros A, et al. Laboratory values for children with newly diagnosed inflammatory bowel disease. Pediatrics 2007;119:1113-9. PUBMED | CROSSREF

22. Howarth LJ, Wiskin AE, Griffiths DM, Afzal NA, Beattie RM. Outcome of childhood ulcerative colitis at 2 years. Acta Paediatr 2007;96:1790-3. PUBMED | CROSSREF 
23. Khan K, Schwarzenberg SJ, Sharp H, Greenwood D, Weisdorf-Schindele S. Role of serology and routine laboratory tests in childhood inflammatory bowel disease. Inflamm Bowel Dis 2002;8:325-9. PUBMED | CROSSREF

24. Gryboski JD. Crohn's disease in children 10 years old and younger: comparison with ulcerative colitis. J Pediatr Gastroenterol Nutr 1994;18:174-82.

PUBMED | CROSSREF

25. Revel-Vilk S, Tamary H, Broide E, Zoldan M, Dinari G, Zahavi I, et al. Serum transferrin receptor in children and adolescents with inflammatory bowel disease. Eur J Pediatr 2000;159:585-9. PUBMED | CROSSREF

26. Thomas DW, Sinatra FR. Screening laboratory tests for Crohn's disease. West J Med 1989;150:163-4. PUBMED

27. Van Biervliet S, Smets F, Hofmann I, Degreef E, Hauser B, Bontems P, et al. The course of anaemia in children and adolescents with Crohn's disease included in a prospective registry. Int J Colorectal Dis 2015;30:51-6. PUBMED | CROSSREF

28. Wiskin AE, Fleming BJ, Wootton SA, Beattie RM. Anaemia and iron deficiency in children with inflammatory bowel disease. J Crohns Colitis 2012;6:687-91. PUBMED | CROSSREF

29. Wikholm E, Malmborg P, Forssberg M, Hederos CA, Wikström S. Iron deficiency is common during remission in children with inflammatory bowel disease. Glob Pediatr Health 2016;4:2333794X16633672. PUBMED | CROSSREF

30. Burbige EJ, Huang SH, Bayless TM. Clinical manifestations of Crohn's disease in children and adolescents. Pediatrics 1975;55:866-71. PUBMED

31. Beeken WL. Absorptive defects in young people with regional enteritis. Pediatrics 1973;52:69-74. PUBMED

32. Thayu M, Leonard MB, Baldassano RN, Mamula P. Prevalence of anemia in incident pediatric crohn disease: 177. J Pediatr Gastroenterol Nutr 2005:41:547-8. PUBMED

33. Antunes CV, Hallack Neto AE, Nascimento CR, Chebli LA, Moutinho IL, Pinheiro BV, et al. Anemia in inflammatory bowel disease outpatients: prevalence, risk factors, and etiology. BioMed Res Int 2015;2015:728925. PUBMED | CROSSREF

34. Filmann N, Rey J, Schneeweiss S, Ardizzone S, Bager P, Bergamaschi G, et al. Prevalence of anemia in inflammatory bowel diseases in European countries: a systematic review and individual patient data meta-analysis. Inflamm Bowel Dis 2014;20:936-45. PUBMED | CROSSREF

35. Akhuemonkhan E, Parian A, Miller K, Hanauer S, Hutfless S. Prevalence and screening for anaemia in mild to moderate Crohn's disease and ulcerative colitis in the United States, 2010-2014. BMJ Open Gastroenterol 2017;4:e000155.

PUBMED | CROSSREF

36. Blumenstein I, Dignass A, Vollmer S, Klemm W, Weber-Mangal S, Stein J. Current practice in the diagnosis and management of IBD-associated anaemia and iron deficiency in Germany: the German AnaemIBD Study. J Crohns Colitis 2014;8:1308-14. PUBMED | CROSSREF

37. Ott C, Liebold A, Takses A, Strauch UG, Obermeier F. High prevalence but insufficient treatment of irondeficiency anemia in patients with inflammatory bowel disease: results of a population-based cohort. Gastroenterol Res Pract 2012;2012:595970. PUBMED | CROSSREF

38. Hansen LG, Stella C. Health research data for the real world: the MarketScan databases [Internet]. Ann Arbor (MI): Truven Health Analytics; 2011 [cited 2016 Nov 11]. Available from: http://truvenhealth.com/ portals/0/assets/PH_11238_0612_TEMP_MarketScan_WP_FINAL.pdf.

39. Uhlig HH, Schwerd T, Koletzko S, Shah N, Kammermeier J, Elkadri A, et al. The diagnostic approach to monogenic very early onset inflammatory bowel disease. Gastroenterology 2014;147:990-1007.e3. PUBMED | CROSSREF

40. Regenstrief Institute. LOINC and RELMA complete package [Internet]. Indianapolis (IN): Regenstrief Institute; 2017 [cited 2017 Oct 10]. Available from: https://loinc.org/downloads/relma/. 